\title{
Lacombe, F. J. M (2011). Recursos Humanos: princípios e tendências (2a ed.). São Paulo: Saraiva.
}

DOI: 10.22289/2446-922X.V4N2A11

\author{
Jheniffer Teixeira Bemfica ${ }^{1}$ \\ Constance Bonvicini \\ Cíntia Cristina de Moura
}

A obra do administrador Francisco Lacombe é intitulada "Recursos Humanos: princípios e tendências" está dividida em 14 capítulos, os quais apresentam assuntos relacionados as principais temáticas da área de Recursos Humanos.

A partir da leitura da obra supracitada, ressalta-se que é possível ver o trabalho como realização humana, isto é, fundamental para a vida das pessoas e faz com que o sujeito se relacione e supra ao mesmo tempo suas necessidades. Dessa forma é preciso que se alinhe as demandas da organização com tais demandas do indivíduo, ou seja, um desafio para os profissionais de Recursos Humanos.

O presente estudo apresenta 14 capítulos, o que faz necessário apresentar de forma sucinta cada um deles.

No primeiro capítulo, "O Trabalho, os Recursos Humanos e as Organizações", destacase o que é organização, sendo está um grupo de pessoas que buscam por objetivos comuns de forma organizada. Todos os homens fazem parte das organizações, o que perdura do nascimento até a fase escolar, isto é, as organizações são constituídas por pessoas, locus em que grande parte das suas satisfações são realizadas, sejam elas sociais, culturais e materiais. É tratado neste capitulo também questões relacionadas à qualidade de vida no trabalho, ou seja, momento em que se enfatiza que os indivíduos deixam de ser vistos como máquinas e passam a ser percebidos como seres que conseguem relacionar sua percepção à ação.

Quando ocorre a tentativa de transformá-los em máquinas este estará sendo condenado, o homem pode ser transformado até certo ponto, entretanto isto o tornaria incapaz de reagir às

\footnotetext{
${ }^{1}$ Endereço eletrônico de contato: jhenifferbemfica@yahoo.com.br

Recebido em 22/03/2018. Aprovado pelo conselho editorial para publicação em 01/05/2018.
}

Rev. Psicol Saúde e Debate. Jul., 2018:4(2):148-155. 
variáveis do mundo exterior. Sabe-se, portanto, que existem inúmeras formas de organizar uma empresa, em especial as pessoas que nela estão inseridas. Para que as demandas existentes sejam supridas é necessário que o departamento de Recursos Humanos tenha como foco: selecionar, formar, integrar, e aperfeiçoar um conjunto de indivíduos para que o grupo consiga alcançar os objetivos desejados.

É importante relatar que já no segundo capítulo, "Planejamento dos Recursos Humanos", o autor ressalta que a primeira tarefa desenvolvida pelos Recursos Humanos é a formação da equipe, sendo este um grupo de pessoas, no qual o objetivo do grupo deve ser além dos objetivos individuais. Faz-se necessário pontuar que é importante admitir pessoas certas para o lugar certo, e também saber se "livrar" daquilo que se torna pouco conveniente para organização por isto é importante que os funcionários sejam constantemente avaliados e aperfeiçoados em suas habilidades, criando ambiente agradável para atrair e retê-los na organização. Na administração é recomendado que sempre se admita os melhores. Logo, o objetivo é atingir os planos da empresa. Um dos pontos de partida para a formação de uma equipe, se baseia no planejamento estratégico, ou seja, metas a serem alcançadas, sendo seu ponto de partida o diagnóstico organizacional desenvolvido pelos dirigentes de alto nível da empresa, onde sejam levantado pontos fortes e fracos da organização, entretanto é necessário serem reavaliados constantemente, uma vez que as pessoas estão em constantes transformações.

Logo, vários assuntos são discorridos no capítulo, pontua-se a importância das avaliações nas organizações, as quais não podem ser totalmente objetivas e sem grau de subjetividade, porém, é importante que plano de avaliação seja o menos subjetivo e distorcido possível, erros e distorções podem ocasionar comprometimento nos resultados e conduzir a decisões erradas

Para tanto, inúmeros tipos de avaliações são realizadas, dentre elas: avaliação

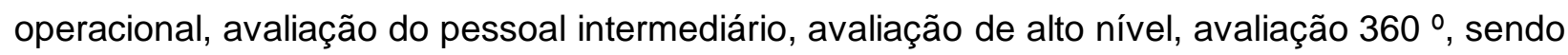
importante ao final do processo, a realização do Feedback como prática habitual, para que este não gere desconforto quando for necessário fazê-lo novamente. O objetivo da avaliação é conduzir alguma recompensa ou punição, não necessariamente uma promoção.

Intitulado "Recrutamento, Seleção, Admissão e Desligamento" o terceiro capítulo aborda temáticas sobre a importância dos procedimentos a cima citado, para formação de uma equipe eficaz. Assim, o processo de recrutamento tem como principal papel, atrair candidatos em potencial para as vagas existentes, havendo dois tipos de recrutamento, o interno e externo, 
sendo o último mais praticado no Brasil. É necessário que se tenha a descrição do cargo a ser ofertado, para que se consiga alcançar o público alvo de forma objetiva. Já o processo de seleção é conjunto de práticas e processos utilizados para escolher dentre os candidatos, aquele que se adequa a vaga ofertada. A prioridade ao selecionar será fazer uma triagem dos currículos, em seguida poderá optar pela entrevista com os candidatos à vaga, para checagem das informações existentes no currículo utiliza-se aplicações testes técnicos profissionais, testes psicológicos e dinâmicas de grupos.

Ressalta-se que não há predeterminação para que as etapas ocorram na sequência. Para tanto, ao constatar a contratação do candidato, o indivíduo irá passar por exames médicos, apresentando junto a empresa as documentações assim necessárias. Logo, a penúltima etapa de um processo de admissão é a integração do colaborador a organização, em que se informa os objetivos, benefícios, politica, normas, práticas e quem é a empresa. Sendo então a última etapa, o período de experiência, determinada pela chefia imediata, desde que não ultrapasse período de 90 dias. A caracterização da entrevista de desligamento conclui o capítulo, descrevendo a importância de uma boa comunicação, a qual normalmente é desempenhada por psicólogos com experiência para conduzir entrevistas deste tipo. As demissões causam grandes impactos na autoestima e na segurança das pessoas, e com bastante frequência essa se torna uma experiência traumatizante na vida dos indivíduos.

O quarto capítulo, "Conduzir para Obter Resultados e Motivação da equipe”, mostra que para se obter resultados através de uma equipe é importante que ela esteja comprometida com as metas, desafios e possíveis riscos que possa encontrar no decorrer do percurso. Sabe-se que existem possibilidades de alcançar resultados a curto prazo cortando treinamentos, oferecendo péssimas remunerações e até mesmo demitindo pessoal, entretanto deve ser avaliado os malefícios que essa ação terá a longo prazo.

Para que ocorra uma boa condução da equipe é de suma importância que haja um administrador que deixe claro os resultados que se almeja, além de estabelecer metas. O gestor deve ser um bom líder, dominar a atividade que está sendo executada pelos liderados e por fim ter uma habilidade humana de criar para os seus subordinados um clima de segurança, compreendendo suas necessidades e suas motivações.

$\mathrm{Na}$ era da administração científica a motivação era vista apenas em questões relacionadas às condições do trabalho no que se diz respeito a luminosidade, ventilação etc.... Foi a partir das experiências de Western Eletric que se explicita a importância da motivação na 
etapa de produção, através das entrevistas realizadas por Elton Mayo muitos trabalhadores se queixavam da perda de identidade, sendo uma evidência de que o trabalho havia perdido todo seu significado. Foram desenvolvidos então, após 1930 estudos sobre o que motivava as pessoas. Em meados de 1940 Abraham Maslow criou as cinco teorias das necessidades sendo estas: auto realização, status, associação, segurança e básicas.

Já para Frederick Herzberg os fatores que motivam a realização do trabalho pelos empregados são os fatores higiênicos como: Diretrizes/administração da empresa, qualidade da supervisão, relações pessoais, condições de trabalho, salários, status e seguranças; e também os fatores motivadores: realização profissional, relacionamento pelos resultados, trabalho interessante, responsabilidade, perspectiva de promoção e aumento de conhecimento. Concluise então que existem inúmeros fatores que motivam, porém para que se possa realmente efetivar é necessário conhecer e identificar suas necessidades, anseios, sendo importante colocar-se no lugar do outro, mesmo que não concorde com a opção ou opinião.

"Remuneração, Incentivo e Benefícios" como é intitulado o quinto capítulo, aborda a importância de uma boa administração de sistema de remuneração, um instrumento que atraí, motiva e retém bons profissionais. Um dos principais fatores de desmotivação é a má remuneração, causando danos não somente em nível material mais também em questões de cunho psicológico. Existem vários tipos de remuneração, dentre eles: Remuneração funcional; Remuneração pelos resultados; Remuneração por habilidade; Remuneração por competência e Sistema misto de remuneração. Independente do estilo de remuneração escolhido, deve-se ater aos impactos que esse terá sobre os resultados.

O capítulo seis "Estilo de Gestão" aborda a priori sobre Frederick Winslow Taylor, o criador da teoria administrativa, que se baseava apenas na obtenção de ganhos através da produtividade. Henry Ford um dos contribuidores da época percebia a qualidade de vida no trabalho, que na época não recebia esse nome, baseada apenas em recompensas financeiras, o que tinha como finalidade o aumento da produção. Como citado anteriormente foi a partir dos estudos feitos por Western Electric Company e Elton Mayo que começou a se preocupar com a importância das relações entre as pessoas para melhora da produção. Likert em seus estudos sobre gestão concluiu que existem dois estilos de supervisores, aquele que está atento ao serviço e o que está atento aos empregados com intuito de motiva-los para alcançar metas.

Para tanto, no sétimo capítulo enfoca-se a "Liderança". Não há possibilidade de se escolher apenas uma dentre as inúmeras definições do termo "liderar", assim não se deve 
descartar a influência que esse tem sobre os liderados, uma organização que não têm bons líderes tem poucas chances de sobrevivência. Dentre as funções desempenhadas por um líder segundo W.J.Reddin está à busca constante em defender os desejos coletivos e criar um espírito de equipe. Já para John Gardner é importante motivar e estabelecer objetivos aos liderados. Entende-se que um bom líder precisa saber se comunicar, criando um clima de confiança, demostrando estar aberto para novos aprendizados, possuir autocontrole, autoconhecimento e ser empático já que este é o combustível para seu sucesso.

Já no oitavo capítulo "O Ambiente Interno da Empresa e o Controle das Relações com o Pessoal" traz informações, descrições sobre o que é cultura organizacional sendo essa, uma conjunção de costumes, normas, crenças e políticas que caracterizam a forma da organização. Dentre as maiores dificuldades para mudanças da cultura dentro de uma organização que possui mesmo padrão a muito tempo é fazer com que se mude a forma de agir e pensar de algumas pessoas, por isso é de suma importância esclarecimentos sobre o porquê de tais. Um dos fatores que influenciam fortemente o clima organizacional, ou seja, o grau de satisfação do pessoal com a empresa é a cultura a qual está inserida, cabendo alinhar os anseios e valores das pessoas com a empresa. Para isso é necessário que os superiores saibam ouvir seus subordinados, possuindo assim canais de comunicação fluídos e adequados, mantendo-os sempre informados e dispostos para receber e dar feedback.

"A Legislação Trabalhista e Previdenciária no Brasil" como foi nomeado o nono capítulo da obra, aborda que a primeira forma de trabalho foi à escravidão, em que o sujeito era apercebido apenas como um objeto e não ser humano. Somente após Revolução Industrial que se tornou prioritária a regulamentação das questões trabalhistas. Somente após a "Carta Del Lavoro de Mussolini" em 1936, que houve no Brasil o início das legislações trabalhistas, consolidando-se através de decreto e leis em 1943.

No capítulo dez "A Importância e os Tipos de Treinamento" aponta a necessidade de capacitar, motivar as equipes constantemente, como fundamento indispensáveis para que o trabalho seja desenvolvido com eficácia, porém este treinamento deve ser utilizado rotineiramente não apenas quando há inserção de um novo membro. Pode-se dividir o treinamento quanto ao público alvo em formação de trainees; capacitação técnico-profissional; estágios; integração de novos empregados e desenvolvimento de executivos. Além disso, como toda ação demanda risco, não seria diferente com o quesito treinamento, muitas empresas investem menos do que o necessário, pois receiam a perda de investimento com o risco daquele 
empregado deixar a empresa e/ou até mesmo pela dificuldade em se calcular os benefícios que este proporciona. A empresa desempenha papel como facilitadora, entretanto o principal responsável pelo seu desenvolvimento são as próprias pessoas.

"Influência da Nova Administração nos Recursos Humanos" capítulo onze, Francisco Lacombe aborda temáticas como o processo de burocratização que possui como intuito a diminuição dos trabalhos repetitivo e o aumento dos que exigem maior qualificação do pessoal. A reengenharia reestrutura os processos das empresas repensando a partir do zero, exigindo também um maior nível de qualificação. Entretanto os administradores não deixaram de se atentar com as pessoas que se "livraram" daquele processo, pensando em reconquistar a lealdade dos sobreviventes. Já o downsizing possuía como objetivo o corte de pessoal para diminuição de nível hierárquico. Quando não bem conduzidos a reengenharia o downsizing pode ocasionar consequências como: diminuição da moral, da segurança, da lealdade e da confiança dos empregados.

Nos dias atuais, uma das principais vantagens competitivas das organizações são o conhecimento das pessoas que a compõe, entretanto este não lhe pertence eternamente, quando um indivíduo deixa a organização sua experiência desaparece com ele. Por isto existe à necessidade das organizações possuírem a capacidade de criar, receber e compartilhar conhecimentos ali adquiridos. Logo, na globalização o mercado exige cada vez mais a qualificação daqueles que a compõe, havendo uma alteração do estilo de profissional desejado, que ao invés de serem especialistas no assunto, se tornem eles generalistas, capazes de adaptar as variáveis exigidas no trabalho.

O capítulo doze nomeado "As Vantagens Competitivas por Meio dos Recursos Humanos" aponta que as vantagens competitivas que se deve dar mais valor dentro de uma organização, são a forma de se administrar as pessoas, porém entende-se que este não seja um trabalho fácil, para isto, se faz necessário criar uma equipe competente, aprimorando sempre que necessário o conhecimento daqueles que a compõe, através de treinamentos, buscando mantê-los sempre motivados e comprometidos com a empresa. Uma das formas de reter e manter bons profissionais é oferecer segurança a equipe, disponibilizando participação nos resultados da empresa ou compras de ações, isto significa compromisso a longo período com a organização. Remunerações também costumam atrair bons profissionais, no entanto há estímulos além de ganhos financeiros como: reconhecimento e realização profissional ou pessoal. Para tanto é 
necessário que haja uma troca transversal de informações entre excetivos de alto nível e seu pessoal, possibilitando assim uma análise maior do grau de satisfação.

"A Importância da Ética" capítulo treze da obra, esclarece que existem inúmeros educadores desde os pais até os chefes das organizações, a partir deste meio cria-se um conjunto de normas e princípios socialmente aceitos como éticos. Com isso as empresas que pretendem permanecer no mercado por muito tempo, devem se pautar na ética, oferecendo confiança e bem-estar aos empregados, fornecedores e clientes, já que este é fundamental para seu sucesso.

O décimo quarto e último capítulo "O Equilíbrio Pessoal: Desemprego, Stress e Trabalho", relembra as primeiras partes do livro, em que hoje diferente de alguns anos atrás, o trabalho é visto como algo que ganha a vida das pessoas, ocupando cada vez mais o tempo de lazer, reflexão de sonhos dos indivíduos. A competição de algumas empresas faz com elas atuem de forma desumanas, oferecendo compensações incoerentes com os esforços de seus funcionários. Com as mudanças ocorridas devido a globalização veio a restruturação da vida familiar, as mulheres deixam de ser presença exclusiva nos lares e passam a atuar em maiores quantidades no mercado de trabalho.

Apesar das mulheres ganharem espaço no mercado de trabalho, no século XXI inicia-se a inserção das tecnologias acompanhadas dessas o agravamento do desemprego. Para alguns autores o trabalho está sendo substituído pelo intelectual e não mais o físico e devido também a diminuição das horas trabalhadas, há a possibilidade de uma pessoa possuir mais de um emprego. Com o excesso de profissionais a disposição, as empresas passam a pressionar os trabalhadores a apresentarem resultados cada vez maiores, causando um aumento do nível de stress, em que um dos fatores é o medo de não conseguir alcançar as metas estabelecidas, criando risco tão temido pelas pessoas, o do fracasso.

Tendo como ponto de partida a Administração é importante salientar o quão grande foi a contribuição dessa para a criação da Psicologia Organizacional e Trabalho. Em que estudiosos da época passaram a perceber as pessoas não como máquinas, mais como indivíduos que possuem desejos, angustias, prioridades e necessidades, surgindo assim a POT.

A presente obra traz aos leitores as mais diversas tendências e perspectivas dos Recursos Humanos no âmbito do trabalho. Em que no seu decorrer, o autor procura elucidar de forma clara e instigante a importância desse, e como a falta ou o desajustamento pode ser primordial para insucesso de uma empresa.

Rev. Psicol Saúde e Debate. Jul., 2018:4(2):148-155. 
Em certos momentos a forma enfática e até mesmo insensível do autor aguça questionamentos, dentre esses o quanto a psicologia e a administração são tão próximas, mas por vezes tão distantes em termos de leitura de emoções e sentimentos e ao se retratarem as dimensões esquecidas na administração. Partindo da interpretação da obra analisada, por diversas vezes Francisco Lacombe utiliza do termo "medíocre" para se referir as pessoas que não possuem desempenho ou perfil como desejado. $O$ autor afirma que quando esta pessoa não estiver sendo conveniente para organização é necessário saber se "livrar" destas eixando claro o ponto que diferencia a psicologia da visão administrativa do autor, já que a primeira está focada no sujeito e a segunda tem como foco a organização.

Entretanto a leitura da obra pode contribuir para que profissionais percebam a importância de uma equipe multidisciplinar nas empresas, tornando um complemento da outra, cujos os objetivos devem ser únicos, o sucesso de pessoas e das organizações. 